\title{
Patterns of Influence and Response in Abusing and Nonabusing Families
}

\author{
Sharon Silber, ${ }^{1,5}$ Eric Bermann, ${ }^{2}$ Melinda Henderson, ${ }^{3}$ \\ and Adam Lehman ${ }^{4}$
}

Behaviors of influence and response during a conflict negotiation task were examined in eight physically child abusing, substance abusing families in which the father was the primary abuser and eight demographically matched nonabusing families. Abusing fathers displayed more coercive patterns of influencing behavior and more negative patterns of response to other family members, including both mothers and children. Fewer differences were observed between mothers in the abusing and nonabusing families or in the children's behavior; however, mothers in the abusing families criticized their husbands more and abused children exhibited less agreement and more criticism toward their fathers. In support of Patterson's theory, abusing families exhibited relatively more reciprocated sequences of criticism and relatively fewer reciprocated sequences of agreement as compared to nonabusing families. Findings are discussed in terms of their implications for understanding interaction in child abusing families.

KEY WORDS: child abuse; family interaction; influence; response.

\section{INTRODUCTION}

In the past 15 years, the research on child abuse has moved steadily toward greater concern with contextualism. That is, investigators have be-

\footnotetext{
${ }^{1}$ Children's Hospital, Family Development, 300 Longwood Avenue, Boston, Massachusetts 02115.

${ }^{2}$ University of Michigan, Ann Arbor, Michigan 48109.

${ }^{3}$ University of South Florida, Tampa, Florida 33620.

${ }^{4}$ Yale University, New Haven, Connecticut 06520.

${ }^{5}$ Current address: Schneider Children's Hospital, Child Psychiatry, New Hyde Park, New York 11042.
} 
come more attuned to how child maltreatment is embedded in interpersonally complex and socially configured circumstances (Belsky, 1980; Wolfe, 1985). Increasingly, researchers have turned to observational methods to describe the complex social transactions that form the context for abuse.

Observational studies of abusive mothers and their children in dyadic interaction have described these mothers both as more intrusive and directive than nonabusing mothers (Lyons-Ruth et al., 1987; Mash et al., 1983) and as less responsive to cues from the child (Crittenden, 1983; Diaz et al., 1990). Additionally, studies of whole families in which the mother is the primary abuser have observed patterns of less frequent, more negative, and less positive interactions, particularly between the abusing mother and her children (Burgess and Conger, 1979; Reid, 1986).

To our knowledge, no prior researchers have employed observational methods to describe family interactions in families where fathers, rather than mothers, are the primary abusers. This is surprising given that epidemiologists have described fathers as being at equal or greater risk than mothers for abuse (Wilson et al., 1980).

In the present study, we use a revealed differences procedure to evoke interaction in two parent families where the father is the primary abuser. In so doing, we draw from a family systems perspective, assuming that family behavior has "coherence" (Dell, 1982), is patterned and repetitive (Baunlin and Schwartz, 1986), and that these recursive patterns are discoverable by observers who view the family interaction.

To describe these recursive patterns, we use a code developed by Bermann (1973) to characterize initiating (here called influence) and response transactions in the family. Influence transactions vary in directiveness from minimally directive (Information Sharing) to highly directive (Control). Response transactions involve reaction to a previous behavior.

Based upon previous studies of abusing mothers, it was expected that abusing fathers would exhibit more coercive influence than nonabusing fathers, as indexed by the relative degree of controlling vs. information sharing behaviors. Abusing fathers also were expected to exhibit more criticism and relatively less agreement to other family members as compared to nonabusing fathers. In addition, based upon characterizations in the clinical literature, abusing fathers were expected to exhibit higher levels of defensive behavior than nonabusing fathers, as indexed by the occurrence of protest.

Family patterns are described both in terms of the characteristic behaviors observed between particular family members and in terms of sequences of behaviors. According to Patterson (1982), abusing families are particularly likely to exhibit escalating sequences of aversive interaction. Thus, abusing and nonabusing families were compared in terms of their tendency to exhibit sustained, reciprocated sequences of criticism, or agreement. 


\section{METHOD}

\section{Subjects}

The subjects for the present study were eight two-parent families who had been referred to Child Protective Services for physical injuries of varying severity, and eight two-parent nonabusing families. In all the abusing families, at least one family member exhibited some abuse of alcohol or drugs. Often, the abusing families exhibited additional forms of violence (wife abuse, neighborhood brawls, etc.) and, in most families, the violence was known or suspected to involve more than one child. In all eight families, the father was the primary (though not always the sole) abuser of the children. Data were collected from the abusing families prior to therapeutic intervention.

Nonabusing families were recruited through churches and community groups. In all cases, the referring person was interviewed by the first author to ensure that abuse had not occurred, and was not occurring. Further, a matched pairs design was used to ensure comparability and to eliminate the potential influence of extraneous factors. Nonabusing families were matched on a family-by-family basis to the abusing sample for race, socioeconomic status (Hollingshead, 1975), number and ages of children (each child was matched within 2 years), and whether the father was employed. Matching for paternal unemployment is important because of findings that unemployment is over-represented among the child abusing population (Cantrell et al., 1990; Steinberg et al., 1991). Use of these elaborate procedures necessarily limited the sample size; it took $1^{1 / 2}$ years to recruit the eight matched nonabusing families.

As expected, there were no significant differences on demographic features. For both samples, the mean age of children was 10.5 , with a range from 2 to 17. SES ranged from Class I to Class V with a mean of Class III (35) for both groups. For both groups, 5 out of 8 fathers were unemployed. All were intact, White families. None was under psychiatric treatment.

Abusing and nonabusing families did, however, differ in the percentage of male children. In the abusing families, $67 \%$ of the children were male. There was no preponderance of male children in the nonabusing families. This finding is consistent with reports that male children are more likely to be physically abused (Wauchope and Straus, 1987).

\section{Procedures}

Data were collected in a University-affiliated clinic prior to therapeutic intervention. To elicit discussion, an interactional task required all family 
members to spend ten minutes deciding upon an area of shared disagreement. This videotaped discussion constituted the data for this study. A transcript was prepared and all verbal remarks were coded. (Procedures for dividing interaction into separate verbal remarks were $>90 \%$ reliable).

\section{Code}

The present code was developed through pilot coding of transcripts not used in the final data analyses. Pilot coding involved simplifying Bermann's (1973) code to fewer categories and eliminating multiple codings. The following categories of influence were defined.

\section{Information Sharing}

A family member brings new information into the interaction: e.g., Son (to Mother): I think we're supposed to come up with something that everybody agrees on.

\section{Guiding Interaction}

A family member attempts to guide conversation in a particular direction or to change the conversational focus: e.g., Father (to Son): What about the thing that Mary mentioned? Chores, I think it was.

\section{Control}

A family member attempts to control the interaction by commanding another family member to do something, e.g., Mother (to Daughter): Now sit down and stop playing.

The following categories of response were described.

\section{Agreement}

A family member expresses agreement with or approval of a previous remark: e.g., Mother (in response to Daughter saying that their biggest problem is discipline): Yes, I think so, too. 


\section{Criticism}

A family member attacks, mocks or antagonizes another family member for a previous remark, e.g., Mother (to Son): Well, that was a stupid thing to say!

\section{Protest}

A family member justifies himself in response to previous criticism. Mother (to Father's question, "Why are you so sneaky?"): I am not sneaky.

\section{Reliability}

Reliability was computed by comparing 200 remarks, drawn from transcripts not used in this study, coded by two independent coders. Kappa reliabilities ranged from .87 to .98 . Values that exceed .60 are considered reliable (Hartmann, 1977).

\section{RESULTS}

\section{Behaviors Exhibited by Family Members}

The percentage of behaviors expressed in each category by fathers, mothers, and children were subjected to a 2 (abuse status) by 3 (person) ANOVA (Saeger and Gabrielson, 1968). An ANOVA was performed for each category of behavior. For Criticism, main effects were found for both abuse status: $F(1,7)=11.64, p<.02$ (abusing families expressed relatively more Criticism than nonabusing families) and person $F(2,14)=6.05, p>$ .02 (fathers expressed greater Criticism than mothers who expressed greater Criticism than children), as well as an interaction effect where abusing fathers expressed relatively higher levels of Criticism as compared to other family members than did nonabusing fathers: $F(1,14)=6.74, p<.03$. For Agreement, an interaction was found where abusing fathers expressed lower levels of Agreement as compared to their wives and children than did nonabusing fathers, $F(1,14)=5.41, p<.04$. For Control, fathers expressed less Control than mothers and children, $F(2,14)=3.83, p<.05$, particularly nonabusing fathers, $F(1,14)=4.61, p<.05$. Figure 1 illustrates these effects.

No main effects or interactions emerged from the ANOVAs for Information Sharing, Protest, or Guiding Interaction, except for a finding that mothers expressed relatively less Protest than their children, $F(1,14)=8.8$, 

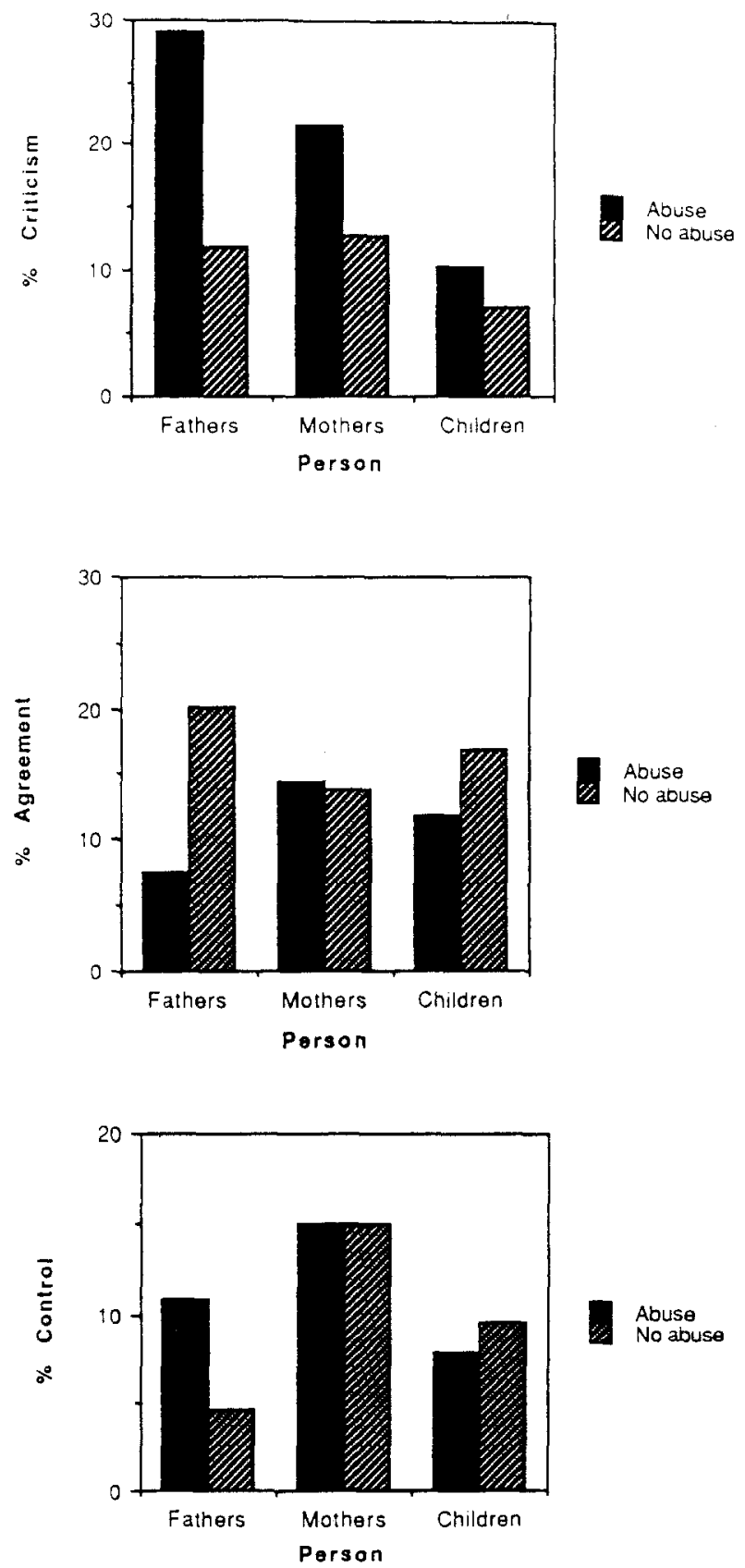

Fig. 1. Percentage of Criticism, Agreement and Control statements exhibited by family members in abusing and nonabusing families. 
$p<.02$. Graphing of results, however, indicated trends toward the greatest divergence occurring in the behavior of the fathers for these categories as well.

\section{Patterns of Interaction Among Family Dyads}

Next, behaviors directed between particular family members were examined (see Table I). Abusing fathers directed more Criticism and less Agreement to their wives than did nonabusing fathers. They also directed more Control, more Criticism, more Protest, less Agreement and less Guiding Interaction to their children. Mothers in abusing families directed more Criticism to their husbands than did mothers in nonabusing families. The two groups of mothers did not differ in the behaviors they directed toward their children.

Children in the abusing and nonabusing families did not differ from one another in their interactions with their mothers or siblings. However, children in the abusing families displayed more Criticism and less Agreement toward their fathers than did the nonabused children. They also directed less Agreement to the family as a group.

\section{Sequences of Agreement and Criticism}

Whereas abusing families followed $19 \%$ of all Agreement with another Agreement, nonabusing families sustained $32 \%$ of all Agreement: $\mathrm{G}^{2}$ $(1)=4.0, p<.05 .^{6}$ Abusing and nonabusing families did not differ in the extent to which they sustained Criticism (in abusing families, $32 \%$; in nonabusing families, $31 \%$ ).

Reciprocated sequences of Agreement or Criticism in which particular family members match Agreement or Criticism remarks (e.g., Mother directs Criticism to Son and then Son directs Criticism back to Mother) were then identified. In abusing families, there were no reciprocated sequences of Agreement ( 0 out of 6 sustained sequences), whereas more than half of the sustained sequences of Criticism were reciprocated ( 9 of 17). In nonabusing families a third of all Agreement ( 7 of 21) and about a third of all Criticism ( 3 of 11 ) were reciprocated. The distributions in abusing and nonabusing families were significantly different: $\mathrm{G}^{2}(1)=9.98, p<.002$.

${ }^{6}$ To compare the distribution of behaviors in abusive and nonabusive families, the $G^{2}$ was used. $G^{2}$ is similar to $\chi^{2}$ in that both measure closeness of fit for contingency table data to a hypothetical model. However, the $G^{2}$ has applications in the present case because it allows partitioning of the contingency table into groups of abusive and nonabusive families. 


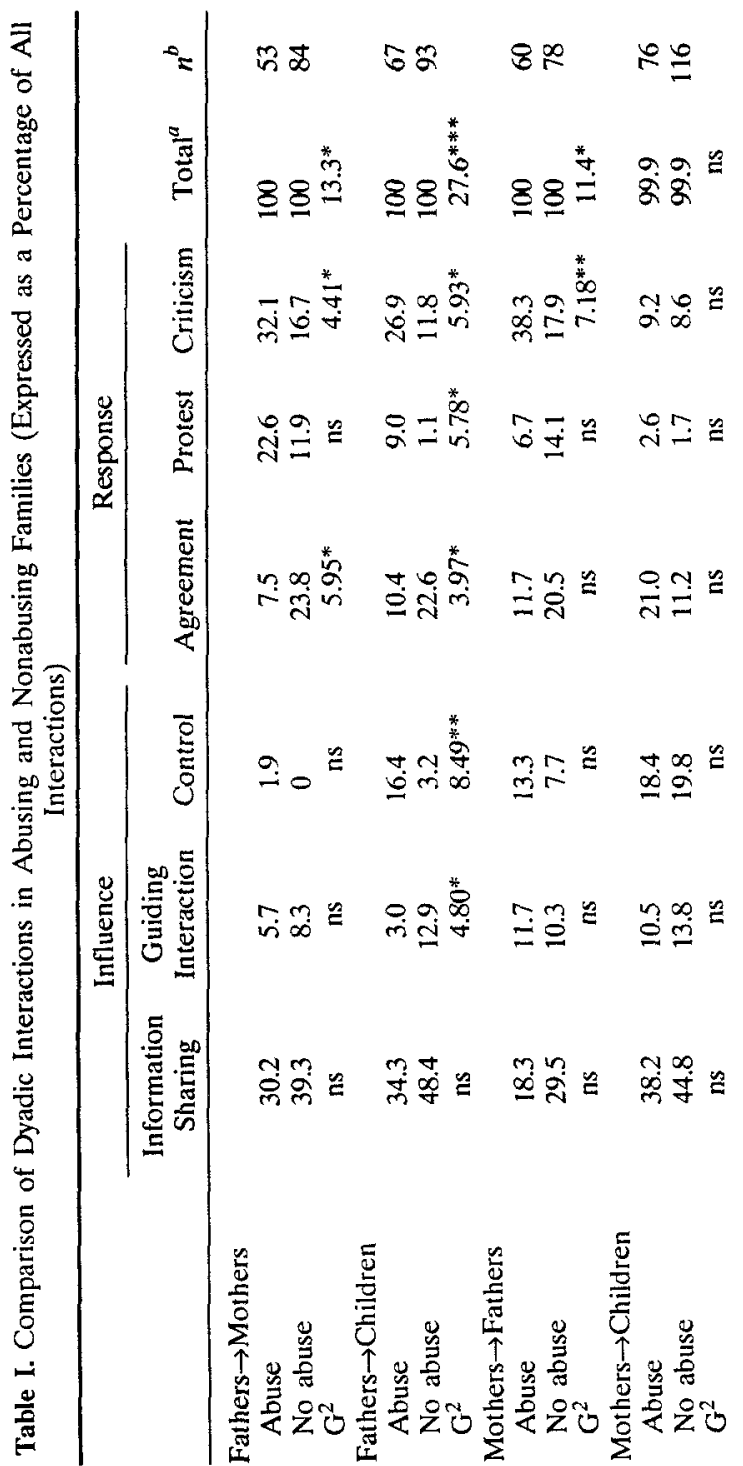




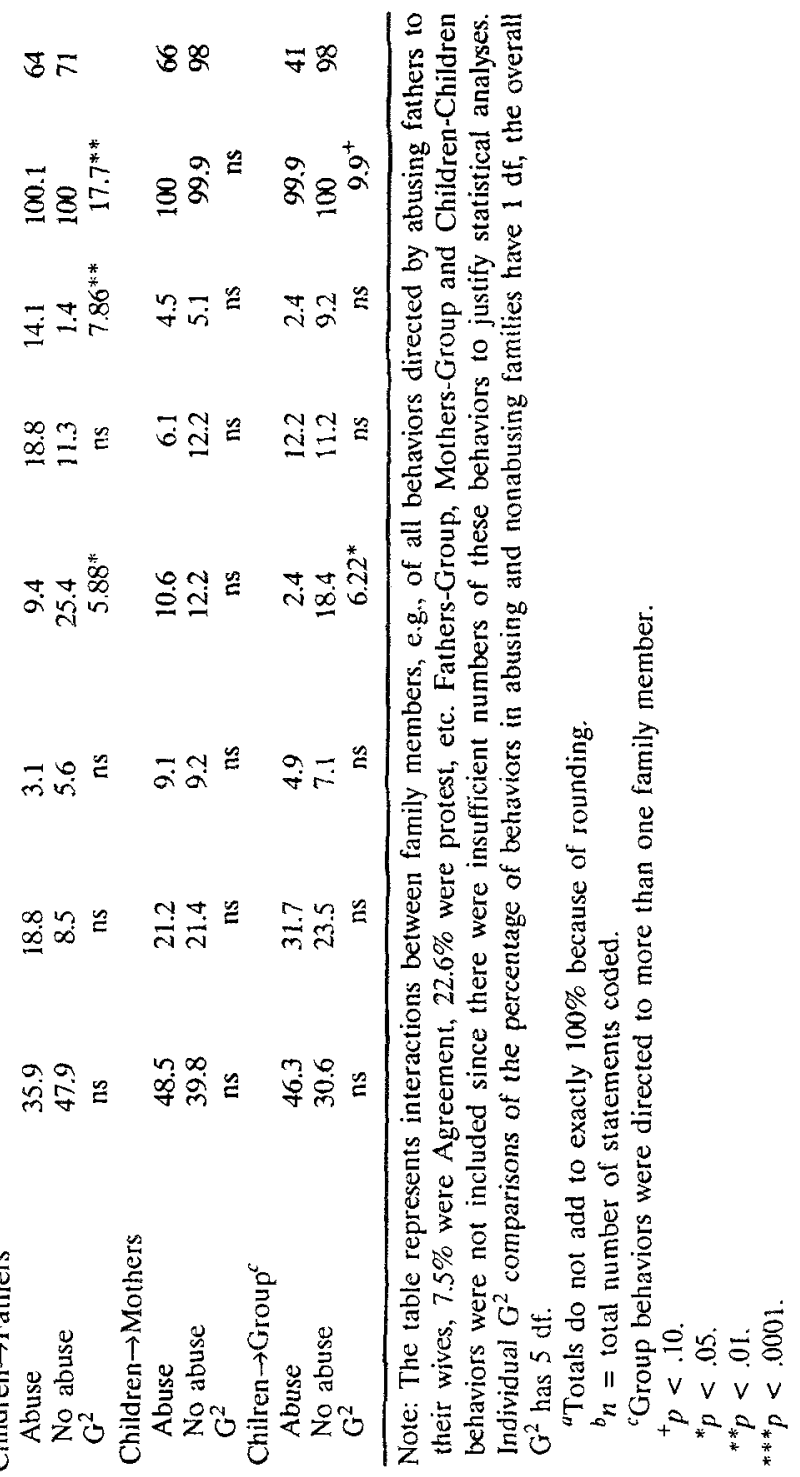




\section{DISCUSSION}

Comparing interaction in physically child abusing families in which the father was the primary abuser and in demographically matched nonabusing families, the clearest differences were evident in the fathers' behavior. Abusing fathers displayed more coercive influence and more critical, less agreeable responses to other family members. Fewer differences were observed between mothers in the abusing and nonabusing families or in the children's behavior. Aversive behaviors displayed by fathers included spousal as well as parent-child interactions, suggesting a possible pattern of "over-flow" from dysfunctional spousal relations. Further, abusing fathers received, as well as exhibited, more critical and less agreeable responses. Thus, findings of more controlling, more negatively responsive behaviors by the abusing fathers, coupled with the relatively greater levels of criticism and lower levels of agreement directed to the abusing fathers by their children and wives, suggest the volatility of the patterns of interaction observed.

Examining sequences of behavior, it was found that, while nonabusing families were equally likely to sustain agreement and criticism, abusing families sustained agreement less frequently than criticism, suggesting that abusing families experience particular difficulty in sustaining supportive interactions. Further, Patterson's theory that abusing families are more likely than nonabusing families to exhibit reciprocated sequences of aversive interaction in which particular family members match critical responses to one another received support in this sample of abusing fathers.

Findings of this study suggest that even a very brief interactional task can elicit significant differences between nonabusive and physically abusive families in which the father is the primary abuser. If replicated, it would suggest a therapeutic strategy which helps the abusing father to utilize less coercive strategies of influence and more positive schemas of response. It also suggests that abusive fathers need to work on evoking, as well as displaying, more agreement and less criticism from their wives and children.

However, further work is necessary to replicate these patterns with a larger sample and to consider the following contextual issues. First, our clinical sample was by definition a "double jeopardy" group, manifesting both child abuse and substance abuse. While these two problems are often associated (Giovannoni and Becerra, 1979, suggest that concordance varies between 40 and $80 \%$ ), interactional differences we found might be associated with substance abuse rather than peculiar to child abuse. Only a third set of matched families in which child abuse was present without the substance abuse, or the substance abuse present without the child abuse, would shed light on this issue. 
Second, in contrast to other studies in which the abusive adult was a mother, our sample is characterized by abusive fathers. This circumstance may provide a different context for understanding abusive transactions, one that links them with the detouring of marital conflict through a scapegoated child. Thus, further work needs to carefully compare the populations of families with abusing mothers and abusing fathers, and to explicate more fully the role of marital conflicts in precipitating child abuse in these two populations.

Finally, as in all studies of identified samples of abusing parents, the generalizability of our results is limited by the process of labeling parents as abusive and thereby stigmatizing them. Such history of social stigma constitutes a significant contextual fabric that may affect the family's participation in the present study, or any experimental procedure, in as yet unexplained ways. Prospective studies in high-risk populations are a means of exploring the role of interactional processes and the evolution of abuse in, as yet, unstigmatized samples.

\section{REFERENCES}

Baunlin, P., and Schwartz, R. (1986). Sequences: Toward a common denominator of family therapy. Fam. Proc. 25.

Bermann, E. (1973). Scapegoat, University of Michigan Press, Ann Arbor, MI.

Burgess, R., and Conger, R. (1978). Family interaction in abusive, neglectful and normal families. Child Devel. 49: 1163-1173.

Cantrell, P., Carrico, M., Franklin, J., and Grubb, H. (1990). Violent tactics in family conflict relative to familial and economic factors. Psychol. Rep. 66: 823-8.

Crittenden, P. (1983). Abusing, neglecting, problematic and adequate dyads: Differentiating by patterns of interaction. Merrill-Palmer Quart. 27: 201-218.

Dell, P. (1982). Beyond homeostasis: Towards a concept of coherence. Fam. Proc. 21.

Diaz, R., Neal, C., and Vachio, A. (1991). Maternal teaching in the zone of proximal development: A comparison of low and high-risk dyads. Merrill-Palmer Quart. 37: 83-107.

Giovannoni, J., and Becerra, P. (1979). Defining. Child Abuse, Free Press, New York.

Hartmann, D. (1977). Considerations in the choice of interobserver reliability estimates. $J$. Appl. Behav. Anal. 10: 105-116.

Hollingshead, A. B. (1975). Four factor index of social status. Unpublished manuscript, Yale University, Department of Sociology.

Lyons-Ruth, K., Connell, D., Zoll, D., and Stahl, J. (1987). Infants at social risk: Relations among infant maltreatment, maternal behavior, and infant attachment behavior. Devel. Psychol. 23: 223-232.

Mash, E. J., Johnston, C., and Kovitz, K. (1983). A comparison of the mother-child interactions of physically abused and non-abused children during play and task situations. J. Clin. Child Psychol. 12: 337-346.

Patterson, G. (1982). Coercive Family Process, Castalia Publishing, Eugene, OR.

Reid, J. (1986). Social interactional processes in families of abused and nonabused children. In Zahn-Waxler, C., Cummings, E. M., and Iannotti, R. (eds.), Altruism and Aggression, Cambridge University Press, Cambridge.

Steinberg, L., Catalano, R., and Dooley, D. (1981). Economic antecedents of child abuse and neglect. Child Devel. 52: 975-985. 
Wauchope, B. A., and Straus, M. A. (1987, July 6-9). Age, class, and gender differences in physical punishment and physical abuse of American children. Paper presented at the Third National Conference on Family Violence Research, University of New Hampshire, Durham, NH.

Wilson, M., Daly, M., and Weghorst, S. (1980). Household composition and the risk of household abuse and neglect. J. Biosocial Sci. 12: 333-340. 